\title{
nature
}

\section{New research council needed}

Ad hoc collaborations between Europe's national funding agencies need to be complemented and, to some extent, replaced by a funding agency charged with supporting outstanding researchers from across the continent.

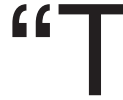
here is nothing more difficult and dangerous, or more doubtful of success, than an attempt to introduce a new order of things in any state. For the innovator has for enemies all those who derived advantages from the old order of things, whilst those who expect to be benefited by the new institutions will be but lukewarm defenders. This indifference arises in part from fear of their adversaries who were favoured by the existing laws, and partly from the incredulity of men who have no faith in anything new that is not the result of well-established experience."

This sixteenth-century quote by Niccolò Machiavelli is one that Wilhelm Krull, secretary-general of Germany's Volkswagen Foundation, likens to the task of those like him who share a bold vision of a European Research Council (ERC) that is independent of the European Commission and national research bodies, and has a mandate to fund basic and strategic research anywhere in Europe on the sole basis of scientific excellence and innovation.

Krull's assessment would have been echoed by Pierre Werner, a European visionary who died last month but who in 1960 fathered the concept of the euro. The birth of the euro is relevant because, despite the many questions surrounding the raison d'etre of an ERC, creating one is a picnic compared to having persuaded the currency's 12 member states to abandon their beloved deutschmarks, francs, lire and pesetas to adopt a single currency and hand over control of economic policy to a central European Bank.

The euro succeeded because of sustained political commitment at the highest level and unprecedented cooperation among Europe's banks. If an effective ERC is to see the light of day, the same is now needed from national politicians and research agencies.

Why do we need an ERC? In short, because it can help Europe make better use of its scientific resources. A European-wide funding scheme for selected categories of basic research would cause the cream to rise and would focus spending better. It could also help fledgling and unfashionable disciplines to obtain decent levels of support in a few well-funded labs.

Moreover, in areas such as bioinformatics and systems biology there is a shift towards truly multidisciplinary approaches, cutting across departmental boundaries and embracing partnership, rather than competition, between major research universities. Such grassroots network initiatives are growing up all over Europe.

\section{Best practice}

Bringing these initiatives under one roof should rationalize peer review and other procedures. A study of existing best practices of peer review and evaluation should be essential in planning an ERC, and an invaluable exercise in itself from which Europe's various research bodies and networks might learn. It would also facilitate international cooperation - single points of contact, instead of multiple negotiations with national bodies.

The devil is in the details, and several bodies have set up task forces to explore these. A conference in October hosted by the Danish research ministry will gather Europe's scientific elite. Its agenda asks the right questions: do we need an ERC, what should it do, who should pay for it, who should run it, and how do we get there?
There are some fundamental conditions that need to apply. Whoever funds it, an ERC must be politically independent. Critically, it must also avoid the bureaucracy that has characterized the European Union's joint Framework research programmes, and demonstrate an impeccable commitment to scientific excellence.

The ERC's day-to-day operations should be run by scientists for scientists, and their choices used to irrigate Europe's existing research powerhouses rather than compete with them. But it needs political legitimacy and clout. Approval of a strategic vision would be needed from Europe's research ministers.

This arrangement may also help to resolve the question of whether the ERC should be bottom-up, supporting largely investigator-driven proposals, or strategically driven. Most current proposals favour a bottom-up approach, but the ERC will, at least initially, have limited funds, and some strategic oversight of research priorities will be needed if money is not to be spread too thinly. Risky areas of research by outstanding scientists could be one priority, transdisciplinarity another. Decisions will also need to be made as to research areas that would have a clear added value by being managed at a European level, as opposed to through the coordination of existing national efforts.

\section{Funding plan}

Who should fund an ERC? One proposal is that a levy of 5\% could be made on national research organizations. But European Union money should also be considered. Indeed, a case could be made for redirecting some Framework funding, which currently targets economic competitiveness rather than basic research. Charities and nongovernmental organizations might find it worth buying into as well.

Prototypes already exist. The European Science Foundation last year created EUROCORES, which, after a call for proposals and peer review, recommends the best projects for funding. It is then up to national members to decide whether they want to provide funding or not. This has the attraction of avoiding pooling funds - a recipe for political discord, as the research projects supported may not tally with nations' own interests. A similar funding variant is that of the European Space Agency, in which members pay a fixed subscription to a compulsory science programme. But there is also an additional 'optional programme', in which member states can decide whether or not to support a particular project.

Some form of variable geometry seems unavoidable in any ERC, as in practice it will be impossible to get a consensus on anything among the thousands of European research institutions. Even within member states, science agencies jealous of their power are still struggling to coordinate disciplines among themselves. Extrapolate that to 15 countries - and soon to 25 - and you see both the need for an ERC and the problems it faces.

If high-level support for the ERC can be sustained, it is not unrealistic to launch it from scratch as a full-blown agency. In one of several possible pilot schemes there could be several highprofile European research awards in the life sciences, in combination with a fellowship scheme supporting young investigators in setting up research groups in a country other than their own. A job for the European Molecular Biology Organization, perhaps? 